\title{
Erratum to: Learning in School, Home and Community
}

\author{
Gail Marshall ${ }^{1}$ and Yaacov Katz ${ }^{2}$ \\ 1 Gail Marshall and Associates, USA \\ 2 Bar-Ilan University, Israel
}

\section{Erratum to: \\ G. Marshall and Y. Katz (Eds.) \\ Learning in School, Home and Community \\ DOI: $10.1007 / 978-0-387-35668-6$}

The book was inadvertently published with an incorrect name of the copyright holder. The name of the copyright holder for this book is: (c) IFIP International Federation for Information Processing. The book has been updated with the changes.

The updated original online version for this book can be found at DOI: $10.1007 / 978-0-387-35668-6$ 